\title{
Recent articles
}

\section{FEBRUARY 2010}

Underemployment in the UK labour market

Annette Walling and Gareth Clancy

Labour market gross flows data from the Labour Force Survey Jamie Jenkins and Mark Chandler

Regional economic indicators: with a focus on differences in sub-regional economic performances

Sebnem Oguz and Jonathan Knight

\section{MARCH 2010}

An expenditure-based analysis of the redistribution of household income Sonia Carrera

First findings from the UK Innovation Survey 2009

Stephanie Robson and Martin Kenchatt

Implementation of SIC 2007 for the Vacancy Survey

Nick Barford, Jonathan Knight and Bob Watson

Understanding the divergence between output and employment in the UK construction industry

Mavis Anagboso and Yonathan van den Brink

Development of construction statistics

Tony Crook and Graham Sharp

Patterns of pay: results of the Annual Survey of Hours and Earnings

1997 to 2009

Ceri Holdsworth

\section{APRIL 2010}

Labour Force Survey unemployment and benefits durations

Gareth Clancy and Daniel Ker

Disability, education and training

Melanie Jones

CPI and RPI: the 2010 basket of goods and services

Philip Gooding

Incorporating derivatives data in the National Accounts and

Balance of Payments

Paul Cullinane

Civil Service Statistics 2009: A focus on gross annual earnings

David Matthews and Andrew Taylor

Plans for Blue Book 2010

Glenn Everett

Services Producer Price Indices (experimental) - Fourth quarter 2009

Simon Woodsford

\section{MAY 2010}

Recent developments in the household saving ratio

Christopher Davies, Valerie Fender and Barry Williams

Comparing different estimates of productivity produced by the Office for

National Statistics

Mike G Phelps

Labour productivity measures from the ABI: 1998 to 2007

Katy Long

The economic impact of tourism across regions and nations of the UK Tullio Buccellato, Dominic Webber, Sean White, Felix Ritchie and Shadia Begum

Regional economic indicators with a focus on gross disposable household income

Sebnem Oguz and Jonathan Knight

\section{JUNE 2010}

Disadvantaged groups in the labour market Ruth Barrett

The UK's international investment position

Damian Whittard and Jawed Khan

Regional gross value added

Bethan West

Labour disputes in 2009

Dominic Hale

The recording of financial intermediation services within sector accounts

Paul Cullinane

Healthcare productivity

Cristina Penaloza

Methods Explained: Real time data

Graeme Chamberlin

\section{JULY 2010}

Characteristics of the underemployed and overemployed in the UK Helen Tam

Explaining the difference between unemployment and the claimant count Gareth Clancy and Peter Stam

The changing face of public sector employment 1999-2009 David Matthews

The effects of taxes and benefits on household income, 2008/09 Andrew Barnard

SOC2010: revision of the Standard Occupational Classification Peter Elias and Margaret Birch

Measures of economic activity and their implications for societal well-being Blessing Chiripanhura

Measuring investment in intangible assets in the UK: results from a new survey Gaganan Awano, Mark Franklin, Jonathan Haskel and Zafeira Kastrinaki

Developments in Services Producer Price Indices

Kat Pegler, Tracy Jones and Chris Jenkins

Services Producer Price Indices - First quarter 2010 Simon Woodsford

\section{Future articles}

List is provisional and subject to change.

\section{SEPTEMBER 2010}

Hours and employment in the UK economy

Modelling the probability of leaving unemployment into employment or inactivity

Regional Gross Household Disposable Income

Wellbeing - taking forward the Stiglitz recommendations

Measurement of human capital 